\title{
Design Support System application to structural design of mega-yacht
}

\author{
V. Žanić, J. Andrić, P. Prebeg \& K. Pirić \\ L. Radić \\ Navis Consult d.o.o., Part of Rolls-Royce Marine, Rijeka, Croatia
}

Faculty of Mechanical Engineering and Naval Architecture, University of Zagreb, Zagreb, Croatia

\begin{abstract}
Application of the modern ship structural design procedure is presented on the megayacht example for all design phases (concept, preliminary and detail). Benefits of utilization of modern rational design support technique (FEM, optimization, etc.) are demonstrated through achieved results (reduction of weight/cost and increase of safety). Approach which employs full ship FEM model which enables simulation of realistic 3D effects without restricting assumptions proved to be the right choice. Presented work is a result of successful cooperation trough joint work of industry and University of Zagreb research teams and represents an example of modern procedure in structural design of complex ships.
\end{abstract}

\section{INTRODUCTION}

Design Support System (DeSS) contains mathematical models for design analysis and synthesis and the corresponding IT-modules embedded into the interactive design environment. It enable design process evolution and development of the efficient (Pareto optimal) designs. DeSS, based on integrated MAESTRO (MAESTRO, 2011., Hughes et al. 1980., Hughes \& Paik, 2010.)/ OCTOPUS (OCTOPUS, 2009.)/DeMAK (Zanic et al., 2009.)/DeVIEW (Prebeg et al., 2009.), was applied in the structural design of mega-yacht $\left(100^{+} \mathrm{m}\right)$ for Rolls Royce Marine AS Merchant Solutions (RRM).

Based on GA plan developed by VEGAYACHT and the initial structural design made by RRM, structural optimization and analysis of a megayacht (by direct calculations) were performed by University of Zagreb (UZ). Application of DeSS during all design phases was based on the following multiple criteria (attributes, goals): reduction of structural weight, VCG position, vibration levels and, in parallel, increase of the overall structural safety measure. Structural design, for given load conditions, was based on LR Rules/LR SDA (Lloyd's Register, 2004.) guidelines for passenger ships. Supported design process is presented as an example of the modern paradigm of multicriteral decision making for concept, preliminary and detailed design phases.

Concept Design Phase (CDP): Two mega-yacht full-ship coarse mesh FEM models (denoted short and long variant based on different length) with the variable superstructure web frame spacing and different double bottom framing were optimized regarding structural mass combined with control of safety measures and VCG position. Design constraints were scantlings' ratios and min-max values, local vibrations criteria (analytically calculated), and LR safety criteria (Lloyd's Register, 2004 -Part A). The efficient solutions were generated for selection of the preferred design variant (mass/length ratio ranged from 30.14 down to $21.88 \mathrm{t} / \mathrm{m}$ with increase in all safety measures.

Preliminary Design Phase (PDP): main structural scantling of the selected preferred mega-yacht was verified using refined full ship FEM model. Global hull girder and substructure free vibration calculation were performed using FEM to verify acceptance of vibration criteria.

Detail Design Phase (DDP): FEM model was further refined to fine mesh level to suit LR requirements (Lloyd's Register, 2004.-Parts B \& C) for verification of critical structural details: large side screens, windows and side openings; connection of arc structure to hull; critical details in aft ship structure, etc.

The objective of the paper is to:

A. Present the structural Design Support System (DeSS) rationale for the design optimization in which the CDP is the most important phase, since all critical questions are to be resolved in short time by making the most far-reaching decisions regarding ship's safety and costs.

B. Show the need for the Pareto Supported Decision-making (PSD), with safety as one of the objectives replacing the old paradigm where safety is only a constraint, promoting thus 
socially responsible design approach (maximal safety for given assets e.g. weight/cost).

\subsection{DeSS fundamentals}

Using the DeSS environment the Design Problem (DP) has to be interactively defined and based on steps from Table 1 (DP identification, Design model formulation and DP solution).

Table 2 presents the Operations Research based procedures, as template for generation and filtering of designs on the Pareto frontier (as ultimate competence of structural designer), to be used by stakeholders in Pareto Supported Decision-making (PSD) process.

Corresponding IT-modules from Table 3 are embedded into the interactive design environment enabling the design process evolution and development of efficient design.

Key to DeSS software integration are interfaces between the IT-modules as defined by the mathematical models (functions and their arguments/descriptors) used. Descriptor sets values are the most austere and unique definition of the design object's physical model as processed by the DeSS mathematical models. They are the crucial parts (besides control data) of interfaces of computational IT-modules based on those mathematical models.

Engineering meta-systems $(\pi \ldots \Phi$ in Table 3$)$ are functional groupings of the mathematical models and corresponding IT-modules enabling easier task integration and process control. All three tables present the taxonomy for standard DeSS methodology (Zanic, 2013) adopted for problem at hand.

DeSS is integrated as ordered set of mathematical modules (direct and surrogate) for design analysis and synthesis.

DeSS basic architecture can be summarized as a cascade ('babushka' style) starting with Level A (interactive 'navigation' of decision support models and modules) and ending with Level $\mathrm{H}$ for structural modeling*:

$$
\begin{aligned}
& \left\{{ }_{\mathrm{A}} \operatorname{SyMd}\left[_{\mathrm{D}} \text { AnMd }\right]_{\mathrm{D}}\right\}_{\mathrm{A}} \\
& =\Gamma\left\{_{\mathrm{A}} \Delta^{\mathrm{k}}\left[{ }_{\mathrm{A}} \Sigma^{\mathrm{k} 2}\left({ }_{\mathrm{B}} \pi\left\{{ }_{\mathrm{C}} \Omega\left[_{\mathrm{D}} \alpha_{\mathrm{G}}, \alpha_{\mathrm{L}}\left({ }_{\mathrm{E}} \rho\left({ }_{\mathrm{F}} \varepsilon, \Phi\right)_{\mathrm{F}}\right)_{\mathrm{E}}\right]_{\mathrm{D}}\right\}_{\mathrm{C}}\right)_{\mathrm{B}}\right]_{\mathrm{A}}\right\}_{\mathrm{A}} .
\end{aligned}
$$

*/Brackets $\left[{ }_{D}\right]_{D}$ denote content (modules) of level $\mathrm{D}$ in $\left\{_{\mathrm{A}} \cdots\left[_{\mathrm{D}} \cdots\right]_{\mathrm{D}}\right\}_{\mathrm{A}}$ embedded into modules of Level A. $\mathrm{k}$ is design cycle number and $\mathrm{k} 2$ is model iteration number.

Alternatively one may start with level $\mathrm{H}$ (define model in $\boldsymbol{\Phi})$ and end on the interactive shell $\Gamma$

Table 1. Design Problem (DP) definition.

(1) Design Problem identification (conceptual level)

$1.1 \quad$ Determination of design objectives

- Selection of design variables $\mathbf{x}$ among the set of design descriptors $\mathbf{d}$. (Note that parameter $=$ descriptor fixed at given value; property $=$ subset of descriptors, e.g. scantlings defining bracket). $\mathbf{d}^{-}=\mathbf{d x}$

1.2 - Selection of design load conditions and load cases LC (extreme, fatigue, accidental) generating set of load effects $\mathbf{Z}=\left\{\boldsymbol{\sigma}^{\mathrm{LC}}\right.$ (stress); $\boldsymbol{\delta}^{\mathrm{LC}}$ (displ.) for given $\mathbf{d}^{\Phi}$ and $\mathbf{d}^{\varepsilon} ; \mathbf{Z}=\mathbf{d}^{-} \cup \mathbf{z}=$ data container

- Selection of design criteria functions $\mathbf{c}$ (constraints $\mathbf{g}(\mathbf{x}, \mathbf{Z}) \geq 0$, attributes $\mathbf{a}$, design objectives $\mathbf{o}$ and related measures of design robustness/sensitivity/risk rx).

- Note that design objective functions o could be obtained from attribute functions a (or KPIs: key performance indicators), if direction of improvement (min, max) is given.

(2) Design Model formulation (algorithmic level)

2.1 Selection of two basic mathematical models:

- Design Analysis Model (AM) for technical (response, feasibility criteria) and economical evaluations (cost criteria, risk), see Table 3.

- Design Synthesis Model (SM) for objective and subjective decision making, see Table 2 and 3.

- Models AM and SM are converted into sets of IT-modules AnMd and SyMd, see Table 3.

2.2 SM formulation (given AM) includes:

- Design problem manipulation into equivalent but mathematically more convenient form.

- Selection of solution strategies (e.g. optimization techniques $\boldsymbol{\Sigma}$, surrogates $\boldsymbol{\Xi}$ ) for manipulated problem, see Table 2A.

- Development of method for the final subjective selection of preferred design(s) among generated variants based on problem particulars in $\Gamma$ shell interactive modules, see Table $2 B$

- Sensitivity/uncertainty/robustness analysis, Table 2B

(3) Design Problem solution (procedural level)

3.1 Application of the design procedure with practical implementation of selected AnMd inbuilt into the SyMd interactive decision-making shell.

3.2 AnMd/SyMd utilities involved should enable the efficient synthesis (optimization and sensitivity modules, databases, graphics, etc.), possibly based on parallel processing due to the required workload and time available to the given design phase (Tables 2 and 3). 
Table 2. Operations Research Problem for DeSS.

\section{A PARETO FRONT GENERATORS/FILTERS-LEVEL B}

PROBLEM MA - Multi Attribute Decision Making (MADM) solution. Solved by $\boldsymbol{\Sigma}$ optimizers (Table 3).

Generate set of $\mathrm{n}$ designs with $\mathbf{K} \mathbf{P} \mathbf{I}^{\mathrm{n}} \equiv \mathbf{y}^{\mathrm{n}}=\left\{\mathbf{a}\left(\mathbf{x}, \mathbf{Z}^{\mathrm{n}}\right), \mathbf{P}_{\mathbf{f}}\left(\mathbf{a}\left(\mathbf{x}, \mathbf{Z}^{\mathrm{n}}\right)\right)\right\}$ for $\mathbf{x}^{\mathrm{n}} \in \mathbf{X} \geq$ (set of feasible designs with all $\mathbf{g}$ $(\mathbf{x}, \mathbf{Z}) \geq 0)$

PROBLEM MO - Multi Objective Decision Making (MODM). Solved by $\Sigma$ optimizers. Taxonomy given in

Table 3 and part (2B) below:

Extremize $\mathrm{KPI}_{\mathrm{i}} \equiv \mathrm{y}_{\mathrm{i}}=\left\{\mathrm{a}_{\mathrm{i}}(\mathbf{x}, \mathbf{Z}), \mathrm{P}_{\mathrm{f}}\left(\mathrm{a}_{\mathrm{i}}(\mathbf{x}, \mathbf{Z})\right)\right\}$ for $\mathbf{x} \in \mathbf{X} \geq$

Extremize subjective KPI value $\equiv 1_{i}=U_{i} * w_{i}=$

$=\mathrm{v}_{\mathrm{i}}\left(\mathbf{u}\left(\mathbf{r x}\left(\mathbf{a}(\mathbf{x}, \mathbf{Z}), \mathbf{P}^{\mathrm{u}}\right), \mathbf{P}^{\mathrm{v}}\right)\right)$ for $\mathbf{x} \in \mathbf{X} \geq$

PROBLEM PF-Using $\Sigma / \Gamma$ modules filter the non-dominated (Pareto) solutions $\mathbf{D}^{\mathrm{kND}}$, from designs generated in problem MA, based on direction of quality improvement for each objective. (Appl. as second part of

MADM or for multiple MODM runs.)

2B SUBJECTIVE SELECTION ON PARETO FRONT-LEVEL A

PROBLEM PD_-Using $\Gamma$ modules select preferred design $\mathbf{D}^{\text {FIN }}$ on Pareto frontier (see b2). Selection procedure may use:

(b1) normalized attribute functions set

$\mathbf{u}=\left\{\mathrm{u}_{\mathrm{i}}\right\}=\left\{\mathrm{w}_{\mathrm{i}}\left(\mathbf{P}^{\mathrm{u} A H P}\right) \cdot \mathrm{U}_{\mathrm{i}}\left(\mathrm{y}_{\mathrm{i}}, \mathbf{P}^{\mathrm{u} \text { fuzzy }}\right)\right\}: \mathbf{y} \rightarrow \mathbf{m}$ enables mapping of $\mathbf{y}$ to normalized values $\mathbf{m}$, using:

- inter-attribute preferences $\mathbf{P}^{\mathrm{u}}$ fuzzy , defined interactively, containing coefficients of each preference function $U_{i}$.

- intra-attribute subjective preference matrix $\mathbf{P}^{\mathrm{uAH}}$, defined interactively, that allows calculation of the importance factors $\mathbf{w}=\left\{\mathrm{w}_{\mathrm{i}}\right\}=\Lambda,\left(\boldsymbol{\Lambda}\right.$ is an eigenvector of the largest eigenvalue of problem $\left.\left(\mathbf{P}^{\mathrm{uAHP}}-\lambda \mathbf{I}\right) \mathbf{w}=0\right)$.

(b2) subjective value of each design defined using value functions $\mathbf{v}\left(\mathbf{m}^{\mathrm{n}}\right)$ for the design variant $\mathrm{n}$ based on e.g. distance norms $\mathbf{v}=\left\{\mathrm{L}_{\mathrm{p}}\right\}, \mathrm{p}=1,2$ or $\infty$; used w.r.t. the specified target design $\mathbf{m}^{*}$. (see b1)

for subjective selection of the optimal design and modifications in modules $\boldsymbol{\alpha}, \boldsymbol{\varepsilon}, \boldsymbol{\Phi}$.

Basic descriptors, models and/or modules are given for reference in Ch.2 subtitles.

\subsection{Basic ship data}

The vessel is a PASSENGER YACHT with the principal dimensions (descriptors) presented in Table 4 . They are used in the set $\mathbf{d}^{\text {BASIC SHIP DATA }}$ of the structural (physical) meta-system $\boldsymbol{\Phi}$, defined by descriptors: $\mathbf{d}^{\Phi} \equiv\left\{\mathbf{d}^{\text {BASIC SHIP DATA }}, \mathbf{d}^{\text {topology }}, \mathbf{d}^{\text {geometry }}\right.$, $\left.\mathbf{d}^{\text {material }}, \mathbf{d}^{\text {scantlings }}\right\}$. Full GA contains most of the other descriptors fixed by the general designer or owner in sets $\mathbf{d}^{\text {topology }}, \mathbf{d}^{\text {geometry }}$.

The structral designers task is to determine values of variables $\mathbf{x}$ of the structural subsystem i.e.: $\mathbf{x}^{\mathrm{M}} \subseteq$ $\mathbf{d}^{\text {material }}, \mathbf{x}^{\mathrm{S}} \subseteq \mathbf{d}^{\text {scantlings }}$ opened to structural designer, as well as limited number of variables $\mathbf{x}^{\mathrm{T}}$ and $\mathbf{x}^{\mathrm{G}}$ in descriptor sets $\mathbf{d}^{\text {topology }}$ (e.g number of webframes) and $\mathbf{d}^{\text {geometry }}$ (actual spacings of elements) by simultaneously satisfying design constraint sets $\mathbf{g}(\mathbf{x}, \mathbf{Z})$ $=\mathbf{g}^{\mathrm{LR}} \geq 0$ for design load conditions/load cases and extremizing design problem objectives.

Loads specification is the crucial task for the general and structural designer in the definition of the design problem. 'Optimistic' design loads definition leads to unsafe design whereas 'pessimistic' design loads selection leads to heavy design, and jeopardy for its economy. Descriptor subsets for design loads (extreme, fatigue, accidental, etc.) and economy data are given as subsets of set $\mathbf{d}^{\mathbf{z}}$ as $\left\{\mathbf{d}^{\text {pressuresLC }}, \mathbf{d}^{\text {accelerationsLC }}\right.$, $\left.\mathbf{d}^{\text {masses }}\right\}$ and $\left\{\mathbf{d}^{\text {costs }}\right\}$ respectively. Other relevant data (preferences, safety factors or corrosion additions) used above LR requirements, etc. are stored in $\mathbf{Z}$ data container of DeSS.

\subsection{Design process}

Design process is presented below in the abbreviated/synopsis form. DeSS details are given later. Taxonomy used is given in Tables 2 and 3, with the following provisions: Module/model/function type logo is constant. Superscript gives info on subset specifics, subscript on component (e.g. $\mathrm{g}_{3}{ }^{\mathrm{LR}}=$ constraint no. 3 (PCMY) from LR formula in library $\mathbf{g}^{\mathrm{LR}}$, see Table 4 , coded in IT-module $\boldsymbol{\alpha}^{\mathrm{LR}}$, see Table 3). ' 0 ' denotes prototype.

Physical models for vibration analysis, Local and Global (full ship and substructures), do not always coincide. Analytics in STEP 1 are used for definition of variables range ( $\min , \max$ ) for vibration prevention measures. They coincide in STEPS 2 and 3 based on FEM models from $\rho^{\mathrm{FEM}}$, (Ch. 3).

Design Procedure was performed in standard steps:

STEP 1. Prototype $\mathbf{P}^{0} \equiv\left\{\mathbf{d}^{0}\right\}$ evaluation (level, critical areas), using set of analysis modules systems $(\Omega \ldots \Phi$ in Table 3$)$ and calculation algorithm denoted: $\rightarrow$ EVAL, VIB, OPT(MA, MO, PF, PD).

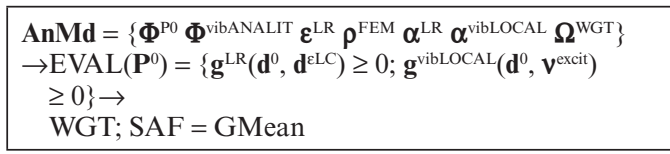


Table 3. DeSS hierarchy of IT-modules.

\section{SM (SyMd IT-modules)_LEVELS A-B}

Level $A$

$\Gamma=$ set of synthesis modules (GUI) in Synthesis Model (SM) for optimization, using preference data $\left(\mathbf{P}^{\mathrm{u}}, \mathbf{P}^{\mathrm{v}}\right)$ for subjective definition of $\mathbf{u}$ and $\mathbf{v}$, designer interaction with the design process, filtering of designs and visualization of $\mathbf{X}, \mathbf{Y}, \mathbf{M}, \mathbf{L}$ sets/spaces spanned by variables and attributes. Output: $\mathbf{m}, \mathbf{l}$.

$\Delta=$ set of modules for the synthesis (optimization) problem interactive definition (selection of variables $\mathrm{x}$ and criteria fn's a and $\mathbf{g}$ via modules $\boldsymbol{\Omega}$, applying problem decomposition and coordination for the large scale problems)

Level $B$

$\boldsymbol{\Sigma}=$ set of optimization solvers for MO and MA PROBLEMs (e.g.: Multi Objective Seq. Linear Programming MOSLP), Fractional Factorial Experiments (FFE), Multi Objective Particle Swarm Optimization (MOPSO), Multi Objective Genetic Algorithms (MOGA), Evolution Strategy-Adaptive Monte Carlo (ES-AMC), etc.) by filtering designs (PROBLEM PF) in $\mathrm{X} \geq \cup \mathrm{Y} \geq$ based on objectives $\mathbf{o}$. Output: Pareto frontier $\left\{\mathbf{x}^{\mathrm{k}}, \mathbf{y}^{\mathrm{k}}\right\}^{\mathrm{ND}}$.

$\boldsymbol{\Xi}=$ surrogate solvers (e.g. Response Surfaces (RS), Kriging, Radial Basis Functions (RBF), etc.) Input: $\operatorname{set}(\mathbf{d}, \mathbf{z})^{\mathrm{n}}$ from fn $\mathrm{c}_{\mathrm{i}}$, Output: quality measure $\mathrm{q}_{\mathrm{i}}(\mathbf{d}, \mathbf{z})^{\mathrm{i}}$.

RBDO modules - LEVEL C (not applied, LR Rules used)

Level $C$

$\pi=$ reliability/robustness meta-system; subset of AM containing modules based on $\mathbf{r x}=\mathbf{R E L} / \mathbf{R O B} / \mathbf{R I S K}(\mathbf{Z})$ fn's. Output: prob. $\mathrm{P}_{\text {fail }}$, risk, robustness measure

Note: Presented DeSS is an update of the parallel processing based procedure (Zanic et al, 1993.) called OCTOPUS. New version is capable of working in MAESTRO/OCTOPUS design environment using very fast reliability calculation module FASTREL (Piric et al, 2013) within design environment (Prebeg et al, 2012).

AM (AnMd IT-modules $\Omega \ldots \Phi)-L E V E L S D-H$

$D$

$\boldsymbol{\Omega}=$ design quality meta-system; subset of AM/SM containing functions/mappings $\mathrm{a}_{\mathrm{i}}$. Output: $\mathbf{y}$.

E

$\boldsymbol{\alpha}=$ adequacy meta-system; subset of modules in the Analysis Model (AM) containing safety (e.g. class. Rules) constraint functions/mappings $\mathbf{g}_{\mathrm{i} \text {. }}$ Output: $\mathbf{I}_{\mathrm{gi}}$ (pass, fail), $\mathbf{g}$-values $[-1,1]$.

F

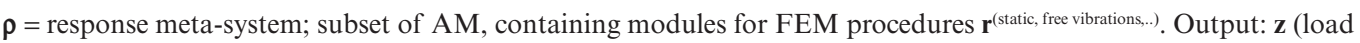
effects).

G

$\boldsymbol{\varepsilon}=$ environment/economy meta-system (loads, costs, etc.); subset of modules in AM with data generators E:

$\mathbf{d}^{\varepsilon}=\left\{\mathbf{d}^{\text {pressuresLC }}, \mathbf{d}^{\text {accelerationsLC }}, \mathbf{d}^{\text {masses }}, \mathbf{d}^{\text {costs }}\right\}=\mathrm{E}\left(\mathbf{d}^{0}\right) \subseteq \mathbf{d}$

Level $H$

$\boldsymbol{\Phi}=$ structural (physical) meta-system; subset of modules/modelers in AM/SM with data generators F generating all necessary information on the structure:

$\mathbf{d}^{\Phi}=\left\{\mathbf{d}^{\text {topology }}, \mathbf{d}^{\text {geometry }}, \mathbf{d}^{\text {material }}, \mathbf{d}^{\text {scantlings }}\right\}=\mathrm{F}\left(\mathbf{d}^{0}\right) \subseteq \mathbf{d}$

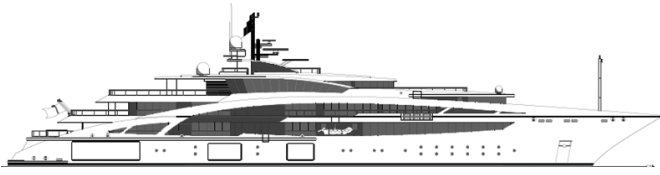

Figure 1. General Arrangement (GA) - Profile (design by VY and RRM).

STEP 2. Structural optimization in CDP for two ship variants: short ' $S$ ' (with options A, B) and long ' $L$ ' (with options $C, D$ ) using control structures $\mathbf{P}^{\text {CS.Fr53-73 }}(\mathbf{x}, \mathbf{Z})$ and $\mathbf{P}^{\text {CS.Fr53-77 }}$ $(\mathbf{x}, \mathbf{Z})$ :
Table 4. Principal dimension.

$\begin{array}{ll}\begin{array}{l}\text { Length overall (long variant } \\ \text { denoted L) }\end{array} & 100.80(\mathrm{~m}) \\ \text { Length between perpendiculars } & 86.875(\mathrm{~m}) \\ \text { Rule length } & 87.378(\mathrm{~m}) \\ \text { Breadth (moulded) } & 16.00(\mathrm{~m}) \\ \text { Depth (moulded) } & 9.85(\mathrm{~m}) \\ \text { Design draught } & 5.55(\mathrm{~m}) \\ \text { Scantling draught } & 5.70(\mathrm{~m}) \\ \text { Displacement at design draught } & 4743(\mathrm{t}) \\ \text { Crusing speed } & 14.0(\text { knots) }\end{array}$

Class notation:

100 A1 Passenger Ship LMC UMS IWS DP(CM) 


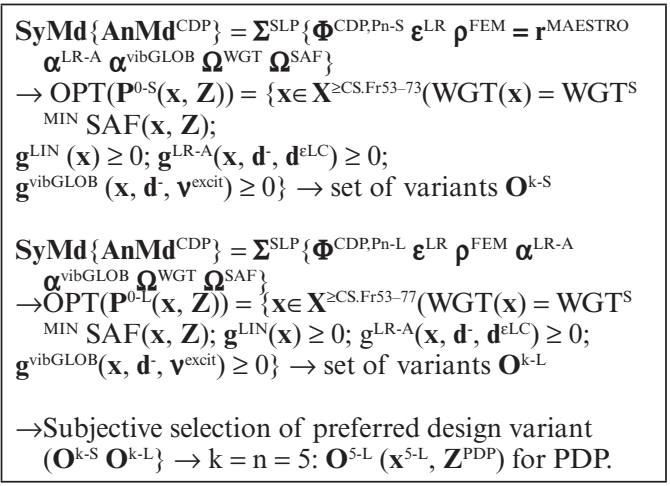

STEPS 3-4. Structural optimization in PDP (preferred long variant (L) with options $\mathrm{C}$ and $\mathrm{D}$ ) and scantlings standardization. Full analysis of the Final Design.

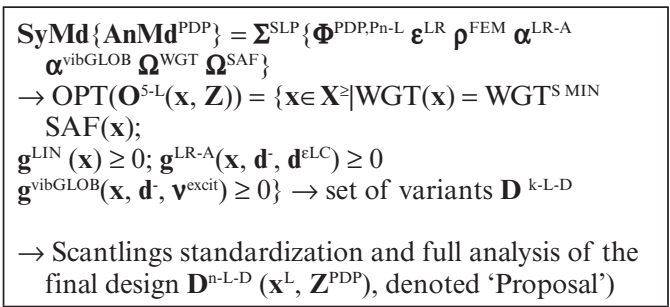

STEP 5. Structural optimization/analysis/redesign in DDP: final design D-Ch. 4):

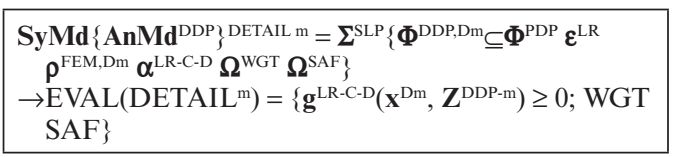

\section{PROTOTYPE $\mathbf{P}^{0}$ ANALYSIS}

The objective of the prototype analysis was mainly defined as verification of global strength and it serves as a basis for further structural optimization and improvement w.r.t weight (objective $o_{1}=$ WGT and safety measure $\mathrm{O}_{2} \equiv$ SAF). The following main aspects were evaluated:

a. structural contribution of the superstructure in resisting hull girder loads and stress distribution over the complete cross-section and length of the ship taking due account of the behaviour and effectiveness of the superstructure;

b. stress distribution in the transverse structure due to racking;

c. force distribution in pillars.

Also, the developed full ship FEM model provided boundary conditions for the fine mesh models required for the investigation of the detailed stress response of the critical structural components.

\subsection{Mathematical model arguments/modules $\left\{\boldsymbol{d}^{\Phi P O} \boldsymbol{d}^{E L R}\right\} /\left\{\boldsymbol{\Phi}^{P O, L R-S D A}=\boldsymbol{\Phi}^{V I B L O C A L} \boldsymbol{\varepsilon}^{L R} \boldsymbol{\rho}^{F E M} \boldsymbol{\Phi}^{B C}\right\}$}

In the view of the non-symmetrical structure $\boldsymbol{\Phi}^{\mathrm{P} 0}$ and racking loads in $\varepsilon^{\mathrm{LR}}$, the entire full ship FEM model was geared to give deflections, stresses and adequacy results and simultaneously provide boundary conditions for further fine mesh detail analysis of all critical areas. The coarse mesh fullship model using ordinary Q4 shell elements and macro-elements (Q4 stiffened panels and hybrid bracketed beam elements) was developed following LR SDA Rules (Lloyd's Register, 2004.).

The global full ship coarse mesh FE model in general followed primary stiffening arrangement, see Figure 2 for reference: (a) longitudinally mesh followed web frame distributions; (b) vertically minimally two elements between decks were inserted; (c) transversely sufficient number of elements was inserted to maintain satisfactory panel aspect ratio (below 1:3), but in most of the structure one element between stiffeners was implemented. All window openings, door openings, deck openings and shell openings of a significant size were represented. Openings in the girder web were represented by the equivalent web thickness based on the area equivalence. Similarly, the model accurately reflects shell and superstructure side recesses, sweep brackets and superstructure breaks.

All implemented structural descriptors/properties (scantlings $\mathbf{d}^{\mathrm{S}}$ ) were based upon documentation supplied by the client. Corrosion deduction of $\mathrm{t}_{\mathrm{k}}=1 \mathrm{~mm}$ was taken only for structural elements in ballast tanks (plates, stiffeners, frames). For other structural parts no corrosion deduction was taken. Full ship 3D FEM response model has 44643 nodes and 88760 macro-elements (stiffened panels) and ordinary FE elements (Q4 shell elements, beams).

Note: To restrain full FE ship model from rigid body motion the artificial supports were placed at the deck (fore and aft ends) and translations were fixed according to LR SDA Rules (Lloyd's Register, 2004.).

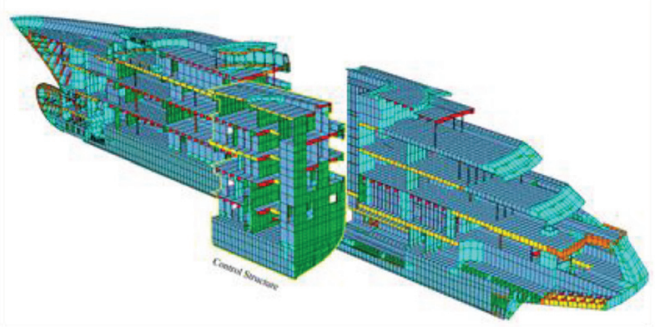

Figure 2. Global FE model of passenger ship and control structure $\left(\mathrm{P}^{\mathrm{CSI}}\right)$. 


\subsection{Loading conditions model arguments/modules $\left\{\boldsymbol{d}^{\varepsilon L R}=E\left(\boldsymbol{d}^{P 0}\right)\right\} /\left\{\boldsymbol{\varepsilon}^{L R}\left(\boldsymbol{L}^{C O} \&\right.\right.$ LR load cases LC) $\}$}

Loading conditions list $\left(\mathbf{L}^{\mathrm{CO}}\right)$ was specified by the documentation provided by the client. The masses specific to each loading condition (tank filling, deadweight masses) together with lightweight masses were included in the model according to 'Loading Conditions' booklet provided by the client. Rule wave bending moments were calculated according to LR Rules (Lloyd's Register, 2010.) with correction due to bow flare and added to the still water bending moments to achieve the distribution required by LR SDA (Lloyd's Register, 2004.). Shear force distribution was also achieved according to the same regulation. Total number of eight load cases was generated, see Table 5 .

FE model was balanced in the quasi-static position as to achieve minimum reaction in the artificial supports. Comparison of the achieved vertical bending moments and vertical shear forces with LR requirements was performed.

\subsection{Prototype response model arguments/modules $\left\{\boldsymbol{d}^{\Phi P O} \boldsymbol{d}^{E L R}\right\} /\left\{\boldsymbol{\Phi}^{P O, L R-S D A} \boldsymbol{\rho}^{F E M}=\boldsymbol{r}^{M A E S^{*}} \boldsymbol{\Phi}^{B C}\right\}$}

*/MAESTRO solver for $\left\{\boldsymbol{\sigma}^{\mathrm{LC}} \boldsymbol{\delta}^{\mathrm{LC}}\right\}$ response fields.

The complete ship 3-D FE model provided results for the global deformations, the distribution of stresses, etc. Displacements of the

Table 5. Load cases.

\section{LC Name}

1 Loading condition L7.1 Max hogging, Sea; (Max. static hogg, still water $):\left(M_{\text {static }}=6.12 \cdot 10^{10} \mathrm{Nmm}\right.$, $\mathrm{Q}_{\text {static }}=-2.66 \cdot 10^{6} \mathrm{~N}$ )

2 Loading condition L4-60\% LC; (Max. static sagg, still water $):\left(M_{\text {static }}=9.36 \cdot 10^{9} \mathrm{Nmm}\right.$, $\left.\mathrm{Q}_{\text {static }}=1.38 \cdot 10^{6} \mathrm{~N}\right)$

3 Loading condition L7.1 Max hogging; (Max. static + wave hogging, sea-going case): $\left(\mathrm{M}_{\text {total }}=1.78 \cdot 10^{11} \mathrm{Nmm}, \mathrm{Q}_{\text {total }}=-6.19 \cdot 10^{6} \mathrm{~N}\right)$

4 Loading condition L4-60\% LC; (Max. static + wave sagging, sea-going case $):\left(\mathrm{M}_{\text {total }}=-1.82 \cdot 10^{11}\right.$ $\mathrm{Nmm}, \mathrm{Q}_{\text {total }}=21 \cdot 10^{6} \mathrm{~N}$ )

5 Lightship racking load condition-static heel $30^{\circ}$ - portside down: $\left(\mathrm{M}_{\text {static }}=2.85 \cdot 10^{10} \mathrm{Nmm}\right.$, $\mathrm{Q}_{\text {static }}=-1.81 \cdot 10^{6} \mathrm{~N}$ )

6 Lightship racking load condition-static heel $30^{\circ}$ - starboard down: $\left(\mathrm{M}_{\text {static }}=2.85 \cdot 10^{10} \mathrm{Nmm}\right.$, $\mathrm{Q}_{\text {static }}=-1.81 \cdot 10^{6} \mathrm{~N}$ )

7 Self weight + tanks + deck plate pressure, static: $\left(\mathrm{M}_{\text {total }}=2.38 \cdot 10^{10} \mathrm{Nmm}, \mathrm{Q}_{\text {total }}=-1.88 \cdot 10^{6} \mathrm{~N}\right)$

8 Self weight + tanks + deck plate pressure, wave condition-HOGG: $\left(\mathrm{M}_{\text {total }}=1.65 \cdot 10^{11} \mathrm{Nmm}\right.$, $\mathrm{Q}_{\text {total }}=-6.22 \cdot 10^{6} \mathrm{~N}$ ) full ship FEM model have been analyzed in detail for LC1 to LC8 through contour plot, see Figure 3.

Maximal total displacement is below $20 \mathrm{~mm}$ for all examined load cases. Maximal relative displacement can be identified in the aft part of Main, Upper and Sun deck. The behavior of the ship's structure in terms of the global deformation was considered satisfactory from the structural aspect in all loading conditions considered.

For each load case the longitudinal hull girder membrane stress fields $\left(\boldsymbol{\sigma}_{\mathrm{x}}^{\mathrm{LC}}\right)$, transverse stress fields $\left(\sigma_{\mathrm{y}}^{\mathrm{LC}}\right)$, shear stress fields $\left(\tau^{\mathrm{LC}}\right)$ and Von Mises equivalent stress fields, for the full and half ship models have been evaluated. Relatively low level of $\sigma_{\mathrm{x}}$ hull girder stresses was identified. The reason for that is that superstructure actively participates in hull girder bending. Connections of lower hull and superstructure are realized through the side arch structure and longitudinal/ transverse bulkheads. Several structural parts have been identified as critical and evaluated in more detail:

- Decks and Longitudinal bulkheads in superstructure have to be checked against buckling. Maximum longitudinal compressive stresses occurred in superstructure in sagging case LC4.

- Transverse Bulkheads (TBHD) represent large transverse stiffness of the ship and highly contribute in transverse strength w.r.t unsymmetrical (racking) loads which are representing through load cases LC5 and LC6. In general, larger stresses are identified above the door openings in each TBHDs $\rightarrow$ stress levels control is required.

- Pillars support decks and they are mainly axially loaded, but also, in addition, some bending stresses can occur, cross sections with the correct buckling capability have to be chosen.

- Identification of highly stressed area that will be finally re-designed and evaluated using fine mesh FE analysis, see Ch. 4.

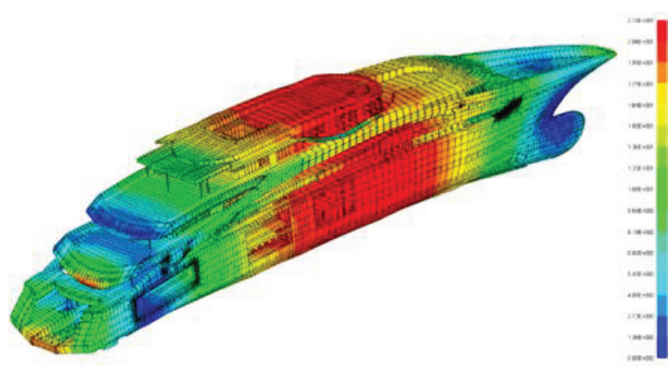

Figure 3. Vertical displacements for load case LC3Max. Hogging. 
2.4 Structural safety assessment model functions/ arguments/modules $\left\{\boldsymbol{g}^{L R}\left(\boldsymbol{d}^{\Phi P 0} \boldsymbol{Z}^{\varepsilon L R}\right) \geq 0\right\} /$ $\left\{\boldsymbol{d}^{\Phi P 0} \boldsymbol{d}^{\varepsilon L R}\right\} /\left\{\boldsymbol{\alpha}^{L R}\right\}$

Structural adequacy was checked using MAESTRO library of adequacy criteria. Safety factors used in MAESTRO criteria for optimization are given in Table 6. Determination of structural feasibility is at the heart of evaluation/optimization procedure since satisfaction of those criteria is the guarantee of structural integrity. The normalized form of failure criterion (normalized safety factor, adequacy parameter) $\mathrm{g}$ is given in the format:

$-1 \leq \mathrm{g}=(C-S F \cdot D) /(C+S F \cdot D) \leq 1$

where $C$ and $D$ are structural capability (capacity) and demand (load effect) expressed as functions of structural and load parameters. Safe structures are those for which $\mathrm{g} \geq 0$.

$D$ (nominal stresses) are obtained from the FEM response on the level of each macroelements, while $C$ is macroelement capability (e.g. specified minimum yield stress of the material) mostly obtained using the LR Rules formulae.

Applied safety factor SF (= $\left.\gamma^{\text {cLASS }}\right)$ is adjusted to LR Rules acceptance criteria (allowable stresses from Lloyd's Register, 2004.). Buckling safety factors were adjusted to the LR Rules and LR PASS program number 10403.
Criteria in Table 6 are divided into groups depending on the part of structure to which they are referred i.e. stiffened panels (stiffeners and plate between stiffeners), frames and girders.

It can be concluded that structure was well designed with a solid reserve. Critical structural elements were identified. Small structural improvements have been proposed to increase the buckling capability of the deck plating and longitudinal bulkheads in superstructure, see Figure 4. Improved prototype structure represents the basic for further performed structural optimization.

\subsection{Local free vibration model functions/ arguments/modules $\left\{\boldsymbol{g}^{\text {vibLOCAL }}\left(\boldsymbol{d}^{0-L} ; \mathrm{SF}^{V I B}\right.\right.$; $\left.\left.\omega, v^{\text {excit }}\right) \geq 0\right\} /\left\{\boldsymbol{d}^{\Phi P 0} \boldsymbol{d}^{E I B}\right\} /\left\{\boldsymbol{\Phi}^{\text {vibLOC }} \boldsymbol{\mathcal { E }}^{\mathrm{vibLOADS}}\right.$ $\rho^{A N L I T v i b}\left(\right.$ or $\left.\rho^{\text {FEMvib }}\right) \alpha^{\text {vibLOC }}$}

In addition to strength analysis the global hull girder and substructures free vibration calculations (dry/wet) were performed to verify acceptance of vibration criteria, as a first step towards forced vibration calculations.

The vibration level of ship structures increase considerably if their natural frequencies $(\boldsymbol{\omega})$ coincide with, or are close to, the excitation frequency of interest ( $\left.\boldsymbol{v}^{\text {excit }}\right)$. Vibration level at resonance my cause discomfort of crew members and passengers and may also cause structural fatigue problems. The resonance risk of the ship structure is normally checked by following steps:

Table 6. MAESTRO Structural adequacy constraints $\mathbf{g}^{\text {LR-NL }}$.

\begin{tabular}{llll}
\hline No. & Limit state & Description & $\gamma$ \\
\hline 1 & PCSF & Panel Collapse-Stiffener Flexure & 1.12 \\
2 & PCCB & Panel Collapse-Combined Buckling & 1.12 \\
3 & PCMY & Panel Collapse-Membrane Yield & 1.06 \\
4 & PCSB & Panel Collapse-Stiffener Buckling & 1.12 \\
5 & PYTF & Panel Yield-Tension Flange & 1.33 \\
6 & PYTP & Panel Yield-Tension Plate & 1.33 \\
7 & PYCF & Panel Yield-Compression Flange & 1.33 \\
8 & PYCP & Panel Yield-Compression Plate & 1.33 \\
9,10 & PSPB & Panel Serviceability-Plate Bending & 1.33 \\
11 & PFLB & Panel Failure-Local Buckling & 0.9 \\
12 & GCT & Girder Collapse Tripping & 1.06 \\
13 & GCCF & Girder Collapse Compression Flange & 1.06 \\
14 & GCCP & Girder Collapse Compression Plate & 1.06 \\
15 & GYCF & Girder Yield Compression in Flange & 1.33 \\
16 & GYCP & Girder Yield Compression in Plate & 1.33 \\
17 & GYTF & Girder Yield Tension in Flange & 1.33 \\
18 & GYTF & Girder Yield in Tension in Plate & 1.33 \\
$19-21$ & FCPH & Frame Collapse, Plastic Hinge & 1.58 \\
$22-24$ & FYCF & Frame Yield, Compression, Flange & 1.58 \\
$25-27$ & FYTF & Frame Yield, Tension in Flange & 1.58 \\
$28-30$ & FYCP & Frame Yield, Compression in Plate & 1.58 \\
$31-33$ & FYTP & Frame Yield, Tension in Plate & 1.58 \\
\hline & & &
\end{tabular}




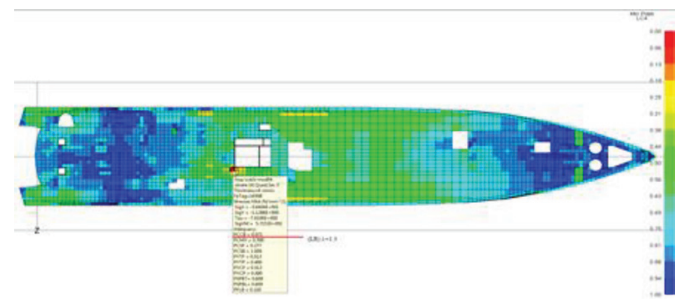

Figure 4. Worst normalized safety factor achieved in plating for all criteria at Main deck for LC4.

1. Calculation of the natural frequencies of all sub-structures in vibration critical areas,

2. Determination of relevant excitation frequencies set $v^{\text {excit }}$,

3. Comparison of the natural frequencies with the relevant excitation frequencies,

4. If danger of resonance exists, alteration of structural scantlings is needed.

Free vibration analysis of the ship has been performed on three levels:

Pre CDP: Local free vibrations of structural parts (plate field, stiffeners) - Analytical approach;

PDP Global hull girder free vibrations - using full ship FEM model (see Sec 3.7);

Post PDP Substructures free vibrations (deck grillages)-using full ship FEM model (ibid).

Based on the Client request sub-critical design approach is chosen. That means that the natural frequency of the structure has to be higher than the relevant excitation frequencies.

The analytical approach based evaluation of vibration levels has been performed in CDP during initial scantling determination as:

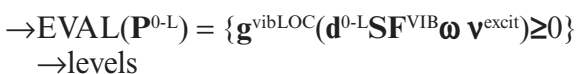

Although the analytically calculated natural frequencies may be less accurate that those found by FE calculation this approach is intended for use at an early design stage of structural design, namely when the general plating and stiffening concepts of the vessel are to be decided upon and during initial scantling determination.

The client specified that the estimated fundamental natural frequency of each part of the stiffened panel (plate and stiffeners) must be at least $15 \%$ grater then the relevant excitation frequency of interest $\left(\mathrm{SF}^{\mathrm{VIB}}=1.15\right)$.

The results and modifications obtained through this analysis were the base for improvements of structural scantlings on the local level (plate thickness and stiffener profile scantlings) during the process of development of classifications drawings. Also, the obtained minimum scantlings w.r.t local vibration served as a constraint (minimum requirement) for the process of ship structural optimization.

\section{CDP/PDP STRUCTURAL OPTIMIZATION USING $\Sigma^{\text {MOSLP }}$ SOLVER}

This Chapter presents optimization process for generation of the design proposals for the longer ship (denoted $\mathbf{D}^{\mathrm{n}-\mathrm{L}}$, where $\mathrm{k}=\mathrm{n}$ is its design cycle) denoting respective design variant, starting with prototype $(\mathrm{n}=0)$. Synopsis of model functions, arguments, associated IT-modules, calculation algorithm for Steps 1-5 are given in Sec. 1.3.

\subsection{Design process and design variants}

Optimization process started from the longer ship prototype (denoted $\mathbf{P}^{0}$ ). Using optimization package MAESTRO/DeMak the optimal designs (denoted $\mathbf{O}^{\mathrm{n}}$ ) were generated. By applying standardization to some scantlings, the design for the preferred longer ship $\mathbf{D}^{\mathrm{n}-\mathrm{L}}$ was finally obtained.

The structural scantlings, of the longer ship prototype $\mathbf{P}^{0-\mathrm{L}}$, above the inner bottom were defined based on the results from previously performed structural optimization of the "shorter ship" design variant-option A (denoted $\mathbf{D}^{\text {n-S-A }}$ ) with topology and geometry descriptors $\mathbf{D}^{\mathrm{T}-\mathrm{A}}$ and $\mathbf{D}^{\mathrm{G}-\mathrm{A}}$ and spacing of beams $=1200 \mathrm{~mm}$. Design variant-option B of the shorter ship (reduced number of beams above inner bottom-spacing of beams $=2400 \mathrm{~mm}$ ) is denoted $\mathbf{D}^{\mathrm{n}-\mathrm{S}-\mathrm{B}}$. Due to special design requirements on the shorter ship structure, its transversely stiffened double bottom has extraordinary strength (small distance between floors $(600 \mathrm{~mm})$, very thick plates for floors and outer shell).

The prototype for the design of longer yacht with option $\mathrm{C}$ (denoted $\mathbf{P}^{0 \text {-L-C }}$ ) was obtained using transverse framing in double bottom like in designs $\mathbf{D}^{\mathrm{n}-\mathrm{S}-\mathrm{A}}$ and $\mathbf{D}^{\mathrm{n}-\mathrm{S}-\mathrm{B}}$.

The prototype variant with option $\mathrm{D}$ for the new design (denoted $\mathbf{P}^{\text {O-L-D }}$ ) was obtained incorporating the following topological changes $\mathbf{x}^{\mathrm{T}}$ into the double bottom structure.

The double bottom topological changes have been implemented in the area between Fr. 53-117:

- Web floor spacing has been extended to $1200 \mathrm{~mm}$ (every second (alternate) floor of the prototype has been excluded);

- Double bottom direction of stiffening was considered as design parameter. The design variant to be further optimized was longitudinally stiffened (inner bottom, outer shell and longitudinal double 
bottom girders). If design objective was cost, both stiffening directions ( $T, \mathrm{~L}$ ) should be compared.

The geometry and topology of all tanks in double bottom structure (Water ballast, Fuel oil, Technical water, etc.) have not been changed, and watertight and tank bulkheads remain on the same position.

Due to topological structural changes specified for the double bottom, the rest of the structure above inner bottom has been exposed to different global stress distribution. This part of the structure has also been optimized w.r.t. to structural scantlings.

\subsection{Design models arguments and IT modules}

AM and SM arguments/descriptors for ship model $\mathbf{P}^{\mathrm{k}}$ to be built according to LR Rules are elements of set $\left\{\mathbf{d}^{\mathrm{\Phi Pk}}\right.$ - physical model $\mathbf{d}^{\mathrm{EL}}$-load model $\}$ while

$\Gamma^{\mathrm{CONTROL}}=\{$ data for design process control $\}$

Analysis model is based on the FEM procedure that follows Lloyd's Register requirements. It was performed with MAESTRO analysis/evaluation software.

AM modules set AnMd $=\{$ response $\} /\{$ evaluation $\}$ $=\left\{\boldsymbol{\Phi}^{\mathrm{P} 0, \mathrm{LR}-\mathrm{SDA}}=\boldsymbol{\Phi}^{\mathrm{vibLOC}} \boldsymbol{\varepsilon}^{\mathrm{LR}} \boldsymbol{\rho}^{\mathrm{FEM}}=\mathbf{r}^{\mathrm{MAESTRO}} \boldsymbol{\Phi}^{\text {BoundCond }}\right\} /$ $\left\{\boldsymbol{\Omega}^{\mathrm{WGT}} \boldsymbol{\Omega}^{\mathrm{SAF}} \boldsymbol{\alpha}^{\mathrm{LR}} \boldsymbol{\alpha}^{\mathrm{VIB}} \boldsymbol{\alpha}^{\mathrm{VCG}}\right\}$.

Synthesis(Optimization) was performed in OCTOPUS Designer, with integrated MAESTRO analysis/ evaluation component, using optimizer $\boldsymbol{\Sigma}^{(\mathrm{MO}) \text { SLP }}$ with dual formulation inbuilt in OCTOPUS Designer.

SM modules set SyMd $=\{$ Definition $\} /\{$ solution $\}=\left\{\boldsymbol{\Gamma}^{\mathrm{CONTROL}} \boldsymbol{\Delta}\right\} /\left\{\boldsymbol{\Sigma}^{\mathrm{MOSLP}}\right\}$ (see Tables 1-3).

Convergence of the process was achieved by maintaining nodal compatibility for the joined elements (compatibility coordination), i.e. by keeping nodal displacements fixed and iterating the global FEM model to achieve another condition for response stability: nodal forces equilibrium.

\subsection{Structural and loading modules}

Global model of the prototype structure $\mathbf{P}^{0 \text {-L-C }}$ was described in Ch.2.

Structural Model $\boldsymbol{\Phi}^{\mathrm{P} \text {, LR-SDA }}$ Step1 in section 1.3 is analyzed by MAESTRO AnMd. 3D FEM model is defined via groups of macro elements creating the Property Element Group (peG) that, as the name suggests, share the same properties for the definition of elements. A very efficient type of such group is the longitudinally extending strake. Strake consists of stiffened panels, frames and girders with the same properties (scantlings) and is easily modeled with data generator $\mathrm{F}$.
Control structure for concept design optimization was the region between Frames 53-73, (denoted $\mathbf{P}^{\mathrm{CS} .53-73}$ ) as illustrated in Figure 2. It speeds up the design process timing. Optimized variables of Control structure dominate longer part of structure.

Loading model and associated module $\left\{\boldsymbol{\varepsilon}^{\mathrm{LR}, \mathrm{Pn}-\mathrm{L}}\right\}$ contains total number of six design load cases for longitudinal and transverse strength. They were used for optimization runs as a subset of total number of eight load cases used for Prototype analysis (see paragraph 2.2). Selected load cases in set list $\mathbf{L C}=(\mathrm{LC} 3 \ldots \mathrm{LC} 8)$ were:

$\mathbf{d}^{\text {eLC }}=\{$ LC3-L7-Arrival-max-Hogg-stillwater + wave, LC4-L4-60\%-LC-SAGG-stillwater+wave, LC5-LightShip-RACKING-PS down,

LC6- LightShip-RACKING-SB down,

LC7-L7 selfweight+tanks+deckpressure-static,

LC8-L7 selfweight+tanks+deckpres-static+wave\}

Design loading arguments are: $\left\{\mathbf{d}^{\mathrm{ELC}}=\mathbf{E}\left(\mathbf{d}^{0-\mathrm{L}}\right.\right.$, $\left.\left.\mathrm{LC}^{\mathrm{LR}}\right)\right\}$.

\subsection{Optimization model and modules}

Design criteria set $\mathbf{a}$ is inbuilt in the IT-criteria modules $\left\{\boldsymbol{\Omega}^{\mathrm{WGT}} \boldsymbol{\Omega}^{\mathrm{SAF}} \boldsymbol{\alpha}^{\mathrm{LR}} \boldsymbol{\alpha}^{\mathrm{VIB}} \boldsymbol{\alpha}^{\mathrm{VCG}}\right\}$. The objective of the optimization was to reduce structural weight $\left(\mathrm{o}_{1} \in \mathbf{0}\right.$ $\subseteq$ a), while fulfilling strength requirements of the classification society LR, vibration requirements and monitoring vertical center of gravity as one of the important attributes for this kind of a ship.

Design variables set $\mathbf{x} \subseteq \mathbf{d}$ is defined in module $\Delta$ and used by module $\boldsymbol{\Phi}$.

Scantlings $\left(\mathbf{x}^{\mathbf{S}}\right)$ are design variables for prescribed structural members in the applied control structure. Minimal and maximal nominal scantlings were prescribed by the client based also on the LR demands: $\mathbf{x}^{\min } \leq \mathbf{x} \leq \mathbf{x}^{\max }$. Optimization process started from the scantlings taken from prototype option D $\left(\mathbf{P}^{\mathrm{L}-\mathrm{D}}\right)$.

Topological variables $\left(\mathbf{x}^{\mathrm{T}}\right)$ considered, were the number of floors (floor spacing) and stiffening direction in the double bottom structure. Option $\mathrm{D}$ has a reduced number of floors (floor spacing $=1200 \mathrm{~mm})$ with respect to the variant $C\left(\mathbf{P}^{\mathrm{L}-\mathrm{C}}\right)$ (floor spacing $=600 \mathrm{~mm}$ ).

\subsection{Design requirements set $\boldsymbol{g}^{L}$ (linear) in module $\boldsymbol{\alpha}^{L I N}$}

Proportionality requirements were defined, based on experience, in the form of various ratios/ proportions that combine frame, girder and stiffener scantlings (Table 7).

\subsection{Design requirements set $\boldsymbol{g}^{S A F}$ for design safety (nonlinear) in modules $\boldsymbol{\Omega}^{S A F} \boldsymbol{\alpha}^{L R}$}

They are used to form constraints and perform safety analysis. Structural adequacy was checked 
Table 7. Proportionality constraints.

\begin{tabular}{|c|c|c|}
\hline Item & $\begin{array}{l}\text { SCANT. PROPORTION } \\
\text { CONSTRAINTS }\end{array}$ & $\begin{array}{l}\text { MACRO- } \\
\text { ELEMENT }\end{array}$ \\
\hline 1 & $\mathrm{TSW} / \mathrm{TPL}<1.0$ & \multirow{9}{*}{$\begin{array}{l}\text { STIFFENED } \\
\text { PANEL } \\
\text { LONGITUDINAL } \\
\text { GIRDER }\end{array}$} \\
\hline 2 & $\mathrm{HSW} / \mathrm{TSW}<36.0$ & \\
\hline 3 & $\mathrm{HGW} / \mathrm{TGW}<80.0$ & \\
\hline 4 & $\mathrm{BGF} / \mathrm{HGW}>0.2$ & \\
\hline 5 & $\mathrm{BGF} / \mathrm{HGW}<0.8$ & \\
\hline 6 & TGW/TGF > 0.5 & \\
\hline 7 & TGW/TGF $<2.0$ & \\
\hline 8 & $\mathrm{BGF} / \mathrm{TGF}<25.0$ & \\
\hline 9 & $\mathrm{BGF} / \mathrm{TGF}>4.0$ & \\
\hline 10 & $\mathrm{HFW} / \mathrm{TFW}<80.0$ & \multirow{7}{*}{$\begin{array}{l}\text { TRANSVERSE } \\
\text { GIRDER } \\
\text { (FRAME) }\end{array}$} \\
\hline 11 & $\mathrm{BFF} / \mathrm{HFW}>0.2$ & \\
\hline 12 & $\mathrm{BFF} / \mathrm{HFW}<0.8$ & \\
\hline 13 & $\mathrm{TFW} / \mathrm{TFF}>0.5$ & \\
\hline 14 & $\mathrm{TFW} / \mathrm{TFF}<2.0$ & \\
\hline 15 & $\mathrm{BFF} / \mathrm{TFF}<25.0$ & \\
\hline 16 & $\mathrm{BFF} / \mathrm{TFF}>4.0$ & \\
\hline
\end{tabular}

using the MAESTRO library of adequacy criteria. Safety factors used in MAESTRO criteria for optimization are given in Table 6. Determination of structural feasibility is at the heart of the optimization procedure since satisfaction of those criteria, for specified design load cases, is the guarantee of structural integrity.

The total number of constraints evaluated in the control structure is 21466 for 6 load cases, out of which 21458 were satisfied in the optimal structure. The structure had just a few locally unsatisfied panel criteria that were corrected manually.

Based on calculated adequacy criteria (in absence of Level C RBD modules), additional simple deterministic safety measures can be applied, often using sums of all criteria/values, (e.g. MAESTRO Adequacy Index), or sums of only ones which are close or below the limit for the comparison among design variants:

$$
\text { Gmean }=\left.\sum_{i=1}^{n_{p}} \sum_{j=1}^{n_{c}} g_{i j}\right|_{<0.05} ;
$$

Besides structural strength requirements, constraints $\mathbf{g}^{\mathrm{VIB}}$ due to vibration of structural components (stiffeners, plate) have been implemented based on analytical calculation of free local vibration. VCG was monitored with module $\boldsymbol{\alpha}^{\mathrm{VCG}}$ $\subseteq \boldsymbol{\alpha}^{\mathrm{MAES}}$.

\subsection{Global hull girder and sub-structure free vibrations mathematical models/ functions/ arguments (see Sec 1.3 Steps 2-4)}

Calculations have been performed, using module $\boldsymbol{\Phi}^{\text {vibGLOB }}$ for the final proposed full ship 3D FEM model $\mathbf{D}^{\text {LONG-D }}$ (with descriptors set $\mathbf{d}^{\mathrm{vibGLOB}}$ ). MAESTRO software option $\mathbf{r}^{\text {vibFREE }}$ from module $\rho^{\text {FEM-vib }}$ was applied. Calculation was performed for $\mathbf{d}^{\text {vibLOADS }}$ obtained from $\boldsymbol{\varepsilon}^{\mathrm{vib}}$, the specified mass cases based upon loadcases defined for the quasistatic analysis (loading condition full load and minimum ballast). Fluid mass matrix (for wet modes) was automatically implemented using the panel method in-built in MAESTRO software for the specified draught. Comparison of results obtained by eigenvalue solver from FEMAP-NASTRAN and MAESTRO was performed. All relevant results for the natural frequency and mode shape pairs are presented using graphical (color coded) interpretation through the relevant figures. Global hull girder free vibrations based on the full ship 3D FEM model show expected behavior for this type of the vessel regarding frequency range for the fundamental modes, see Figure 5.

Substructure free vibrations based on the full ship 3D FEM model have identified some of the potentially vibrating substructures for which the forced vibration analysis is needed to resolve potential problems on time, see Figure 6. With the proposed scantlings, the sub-critical design cannot be achieved for several substructures with the present design solution. Therefore it was recommended to perform the forced vibration calculations to achieve realistic responses amplitudes (displacements, velocities, accelerations) and to improve the design solution.

\subsection{Comparison of variants and the Decision Support Problem (DSP)}

Table 8 shows comparison of relevant model variants by comparing the control structure weights.

The comments on variants presented in Table 8 are as follows:

- For decision making and comparison of design variants based upon their control structures it is convenient to introduce the quality measure like weight of structure per unit length. It is easier to apply results to both ship lengths.

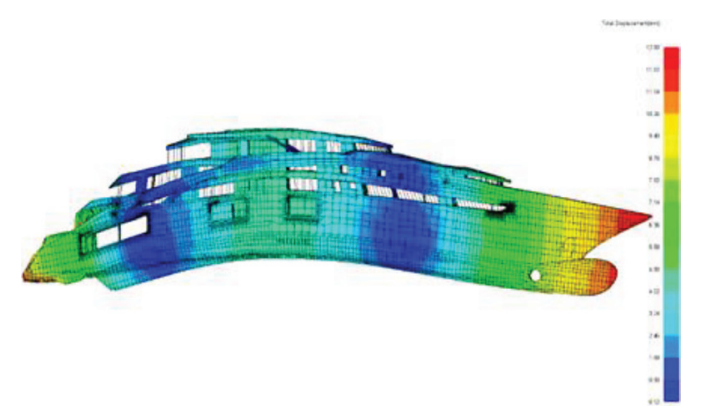

Figure 5. Global hull girder free vibrations (wet mode), $\mathrm{f}=2.73 \mathrm{~Hz}-1$ st vertical mode 


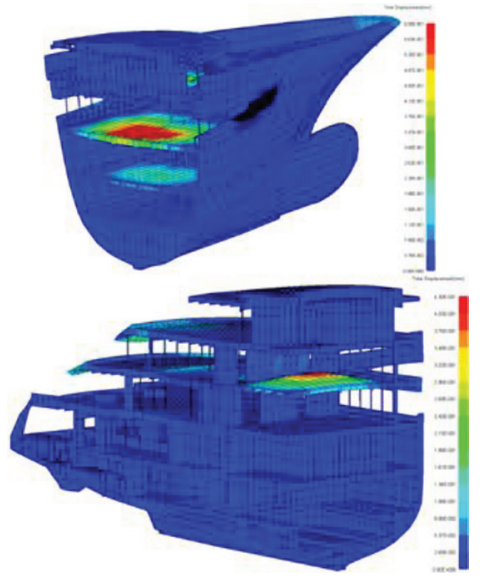

Figure 6. Substructures free vibration of Main deck ( $f=15.86 \mathrm{~Hz}-1 \mathrm{~V})$ and Upper deck ( $\mathrm{f}=15.02 \mathrm{~Hz}-1 \mathrm{~V})$.

Table 8. Comparison of design variants.

\begin{tabular}{|c|c|c|c|c|c|c|c|c|c|c|c|}
\hline \multirow{3}{*}{ 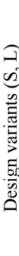 } & \multirow{3}{*}{ 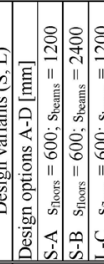 } & \multirow{3}{*}{ 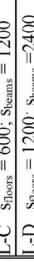 } & \multicolumn{3}{|c|}{$\begin{array}{c}\text { Mass } \\
{[\mathrm{t}]}\end{array}$} & \multicolumn{3}{|c|}{$\begin{array}{l}\text { Mass/length } \\
{[\mathrm{t} / \mathrm{m}]}\end{array}$} & \multicolumn{3}{|c|}{$\begin{array}{l}\text { Relative to } \\
\text { prototype }\end{array}$} \\
\hline & & & \multirow{2}{*}{ 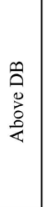 } & \multirow{2}{*}{ 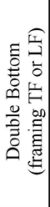 } & \multirow{2}{*}{ 范 } & \multirow{2}{*}{$\begin{array}{l}\text { 常 } \\
0 \\
0 \\
\frac{0}{4}\end{array}$} & \multirow{2}{*}{ 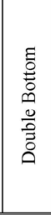 } & \multirow{2}{*}{ 嵒 } & 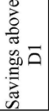 & 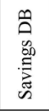 & 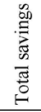 \\
\hline & & & & & & & & & \multicolumn{3}{|c|}{$\begin{array}{l}\text { Prototypes used: } \\
\mathbf{P}^{\mathrm{S}-\mathrm{A}} \text { options A, B } \\
\mathbf{P}^{\mathrm{L}-\mathrm{C}} \text { options C, D }\end{array}$} \\
\hline & 168.7 & 193.0 & 361.7 & 14.06 & 16.08 & 30.14 & 0.00 & FIX & 0.00 \\
\hline \multicolumn{3}{|c|}{ Optimal $\mathbf{O}^{\mathrm{SA}}$} & 152.8 & 193.0 & 345.8 & 12.73 & 16.08 & 28.82 & 0.09 & FIX & 0.04 \\
\hline \multicolumn{3}{|c|}{ Prototype $\mathbf{P}^{\mathrm{S}-\mathrm{B}}$} & 156.7 & 193.0 & 349.7 & 13.06 & 16.08 & 29.14 & 0.07 & FIX & 0.03 \\
\hline \multicolumn{3}{|c|}{ Optimal $\mathbf{O}^{\mathrm{SB}}$} & 139.1 & 193.0 & 332.1 & 11.59 & 16.08 & 27.68 & 0.18 & FIX & 0.08 \\
\hline \multicolumn{3}{|c|}{ Prototype $\mathbf{P}^{\mathrm{L}-\mathrm{C}}$} & 214.6 & 208.6 & 423.2 & 14.90 & 14.49 & 29.39 & 0.00 & 0.00 & 0.00 \\
\hline \multicolumn{3}{|c|}{ Prototype $\mathbf{P}^{\mathrm{L}-\mathrm{D}}$} & 214.6 & 160.1 & 374.8 & 14.90 & 11.12 & 26.03 & 0,00 & 0.23 & 0.11 \\
\hline \multicolumn{3}{|c|}{ Optimal $\mathbf{O}^{\mathrm{L}-\mathrm{D}}$} & 197.4 & 117.6 & 315 & 13.71 & 8.17 & 21.88 & 0.08 & 0.44 & 0.26 \\
\hline \multicolumn{3}{|c|}{ Proposal $\mathbf{D}^{\mathrm{L}-\mathrm{D}}$} & 214.6 & 117.6 & 332.2 & 14.90 & 8.17 & 23.07 & 0.00 & 0.44 & 0.22 \\
\hline
\end{tabular}

Note: control structure for short ship (S) variants was the region between Fr. 53-73 while for long ship (L) variants was the region between Fr. 53-77.

- Relative measure (e.g. weight/length measure) with respect to the predefined prototype value are efficient in contrasting design variants.

- Savings in structure above DB are best achieved by changing of the frame spacing to $2400 \mathrm{~mm}$ (from $1200 \mathrm{~mm}$ ). Savings of $18 \%$ for this part of the structure or $8 \%$ in the weight/length measure have been achieved with positive effect on VCG.

- Savings in DB structure are best achieved by changing of the frame spacing to $1200 \mathrm{~mm}$ (from $600 \mathrm{~mm}$ ). Savings of $44 \%$ for this part of the structure or $26 \%$ in the weight/length measure have been achieved with strong effect on VCG.

- The designer has to decide on the basis of his/ her preferences on the spacing in both structural segments. Extension of results to dominated part of structure/full ship is used for structural safety assessment and ship VCG calculation. Results are given in Chapter 6.

\subsection{Discussion of results for the control structure}

Basic considerations on design objective for longer ship variant: The optimization process has successfully converged to the optimum after 5 cycles (see Fig. 7) with potential for weight reduction (control structure) of about $20 \%$.

Part of these savings was due to change of double bottom structure. Designer may also consider VCG position by changing topology (reduced number of frames) in the structure above double bottom or ballasting the ship differently.

These reductions of the control structure weight were based on the optimization model in which vibration criteria were also included as a minimally permitted scantling values.

Analysis of active constraints $\left(\right.$ tol $^{\min } \leq \mathbf{g}(\mathbf{x}, \mathbf{Z})$ $\leq$ tol $^{\text {max }}$; tolerance $= \pm 0.05$ ) shows that almost all designs were stopped by prescribed $\mathbf{x}^{\mathrm{MIN}}$ values and not by the safety criteria.

Significant safety reserves are present in the optimal design with respect to the applied adequacy criteria set (Table 6) for the prescribed design load cases. It shows that objective $\mathrm{O}_{2}=$ GMean should be activated for the relaxed $\mathbf{x}^{\mathrm{MIN}}$ values.

However, dealing with the safety reserves is only rational within the risk/reliability $\mathrm{RBDO}$ process leading to decrease in risk and better distribution of the maintenance efforts. It requires sea keeping analysis (extreme sea and fatigue loads). Novel MAESTRO modules (in testing) enable it, in particular if connected to ultra-fast Dimension Reduction Method (DRM) combined with bi-distribution failure function (Piric, 2014). Present safety calculation is performed with heuristic safety measures (e.g. GMean) see Figure 7, still showing the attraction of the $\mathrm{o}_{1}$ (WGT) function to the design variants with improved safety (up to ship cycle number 5) when the process have converged.

\section{DETAIL DESIGN PHASE (DDP) MODELS AND MODULES}

SYNOPSIS from Sec. 1.3 states:

$$
\rightarrow \operatorname{EVAL}\left(\text { detail }^{\mathrm{m}}\right)=\left\{\mathbf{g}^{\mathrm{LR}-\mathrm{C}-\mathrm{D}}\left(\mathbf{x}^{\mathrm{Dm}}, \mathbf{Z}^{\text {DDP-m}}\right) \geq 0\right\} \rightarrow \text { WGT }
$$
SAF

for critical ship details $m=1, \ldots$, nd.

The complete ship 3-D FEM model from the preliminary design phase was further refined on

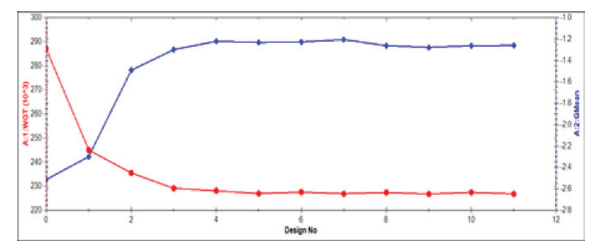

Figure 7. History of weight for longer ship variant option-D with respect to the design cycle number $\mathrm{k}$. 
fine mesh level to suit LR requirements for verification of critical structural details: large side screens, windows and other large side openings, hull to arc structure connection, critical details in the aft ship structure, hull connection with azipull, deck grillage etc., see Figure 8.

The complete ship FE model, with the fine mesh models embedded directly into the coarse mesh model, avoids the need for the generation of separate boundary conditions. The plating and supporting primary structure is represented by the standard Q4 shell elements having both membrane and bending capability.

The results regarding required acceptance criteria, as defined in LR SDA Part B, are checked for each structural item, its critical location, examined load cases, criterion type (average von Mises equivalent stress, peak stresses and dynamic stress range) to demonstrate compliance to LR criteria. Structure was well designed. Critical structural elements were identified and some structural reinforcement (patches of higher thickness plates around sharp/radius corners) or geometry changes were suggested.

\section{CONCLUSIONS ON RESULTS OF DESS APPLICATION TO THE MEGAYACHT DESIGN}

Optimized scantlings, obtained for the control structures, were applied to MAESTRO model of the related design variant. For both ship models the optimal control structure scantlings were applied to the assumed affected region extending from Fr. 53 to Fr. 117.

\subsection{Short ship model}

Ship structure was fully re-analyzed regarding satisfaction of all structural criteria and including some of the provisions regarding vibrations. The

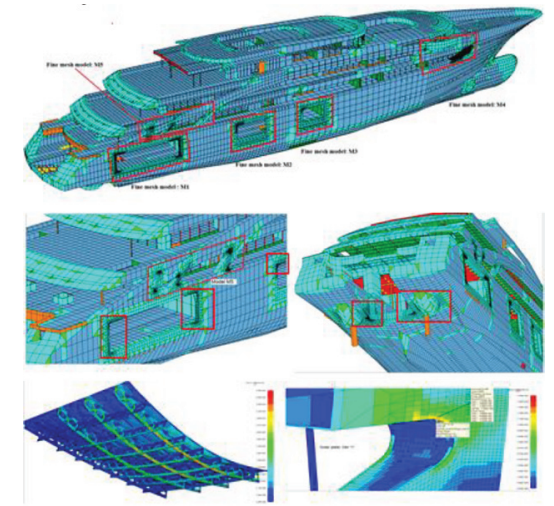

Figure 8. Evaluation and redesign of critical structural details. final results regarding design objectives for the full ship are presented in the Table 9.

Achievements are: 135 tons of weight savings and $110 \mathrm{~mm}$ of decrease in VCG for the full ship due to the changes in the affected region.

\subsection{Long ship model}

Ship structure was fully re-analyzed regarding satisfaction of all structural criteria and including some of the provisions regarding vibrations. The final results regarding design objectives for the full ship are presented in the Table 10 .

Achievement are: 251 tons of weight savings while VCG is increased for $422 \mathrm{~mm}$ due to large decrease of weight in the optimized double bottom structure (permitted).

It opens possibilities of different interplay between VCG and weight based on designer's/ owner's choices of design criteria regarding: ship stability, passenger comfort, selected stabilization system, lighter ship and its consequences on LCC and other performance measures.

One of the advantages of using DeSS is that design variants/models (with different design options) are all optimized and comparable on the level of design objectives.

In the mega-yacht design problem, different combinations of ship attributes/qualities/KPIs can be investigated and presented, as Pareto frontier, to the stakeholders. To select final design the subjective decision making process (see Table 2B) can be performed, more complex than classical VCG vs. weight design problem. Regarding safety it was pointed out in Section 3.8 that safety/risk attributes are best dealt with RBDO to manage safety margins.

Smooth flow of ship model data (descriptor sets) through mathematical models AM and SM and their IT counter parts AnMd MAESTRO and SyMd OCTOPUS have proven to be efficient design tools leading to superior design of the mega-yacht. Next step is inclusion of RBDO option in practical design procedure.

\section{ACKNOWLEDGEMENTS}

Thanks are due to the long-term support of Croatian Ministry of Science, Education and Sports: projects 120-1201829-1671. Thanks are due to the members of the OCTOPUS and BONUM groups (www.fsb.hr/octopus) and (www. bonum.hr), Advanced Marine Technology Centre, DRS Technologies, Inc. (www.drs-ds.com) and Navis Consult d.o.o., Rijeka-Part of Rolls-Royce Marine (www.rolls-royce.com/marine). 
Table 9. Comparison of full Ship Prototype (denoted SPP ${ }^{\mathrm{S}-\mathrm{A}}$ ) and corresponding Optimized Design based on Design variant $\mathbf{D}^{\mathrm{S}-\mathrm{A}}$.

\begin{tabular}{llllll}
\hline Full ship scantlings & Group & Weight(t)/savings & \multicolumn{2}{c}{$\begin{array}{l}\text { VCG(mm)/ } \\
\text { difference }\end{array}$} \\
\hline Prototype SP & Steel selfweight & 1950 & 0 & 6412 & 0 \\
& Light ship & 3783 & 0 & 7031 & 0 \\
Proposed ShipDesign & Steel selfweight & 1815 & -135 & 6138 & -274 \\
SD $^{\text {S-A }}$ & Light ship & 3648 & -135 & 6921 & -110 \\
\hline
\end{tabular}

Table 10. Comparison of full Ship Prototype (denoted SP ${ }^{\mathrm{L}-\mathrm{D}}$ ) and corresponding Optimized Design based on Design variant $\mathbf{D}^{\mathrm{L}-\mathrm{D}}$.

\begin{tabular}{llllll}
\hline Full ship scantlings & Group & Weight(t)/savings & \multicolumn{2}{c}{$\begin{array}{l}\text { VCG(mm)/ } \\
\text { difference }\end{array}$} \\
\hline Prototype SP & Steel selfweight & 2129 & 0 & 6875 & 0 \\
& Light ship & 4123 & 0 & 7360 & 0 \\
Proposed ShipDesign & Steel selfweight & 1878 & -251 & 7647 & +772 \\
SD $^{\mathrm{L}-\mathrm{D}}$ & Light ship & 3872 & -251 & 7782 & +422 \\
\hline
\end{tabular}

\section{REFERENCES}

Hughes, O.F., Mistree F., Zanic V. 1980. A Practical Method for the Rational Design of Ship Structures, Journal of Ship Research: 24, 101-113.

Hughes O.F. \& Paik J.K. 2010. Ship structural analysis and design, Society of Naval Architects and Marine Engineers, New Jersey, USA.

Lloyd's Register. 2004. Structural Design Assessment, Primary Structure of Passenger Ships-Guidance on direct calculations, May 2004.

Lloyd's Register. 2010. Rules and Regulations for the Classification of Ships, Part 3-Ship Structures (General) and Part 4 Ship Structures (Ship Types), July 2010.

MAESTRO Version 9.1. 2011. Software Documentation. DRS-C3 Advanced Technology Center, Stevensville, USA.

OCTOPUS. 2009. Software Documentation. University of Zagreb, Faculty of Mech. Engineering and Naval Architecture.

Piric, K., Kitarovic, S., Zanic, V. 2013. Verification of modified dimension reduction method and sensitivity analysis method with respect to their application in the reliability based design procedures, Proceedings of IMAM Congress, La Coruna, Spain.

Piric K. 2014. Reliability Analysis in Ship Structural Concept Design, PhD thesis, Zagreb: University of Zagreb, Faculty of Mechanical engineering and Naval Architecture (In Croatian).

Prebeg, P., Kitarovic, S., Zanic, V. 2009. The Design Methodology with the Sequencer for Efficient Design Synthesis of Complex Engineering Systems. Proceedings of the 50th AIAA/ASME/ASCE/AHS/ASC Structures, Structural Dynamics, and Materials Conference. Palm Springs, USA.

TECHNICAL REPORTS for RRM AS Merchant Solutions by University of Zagreb, Authors: Zanic, V., Andric, J., Piric, K., Grgic, M., Stipcevic, M. (available by permission of RRM).

Technical Report 102-300: LR-1, 2011a. Full ship FE analysis of passenger ship: P11-02458 VEGAYACHT
100.8 m KUSCH YARD_Global Response Analysis (Part A), November, 2011.

Technical Report 102-300: LR-2, 2011b. Full ship FE analysis of passenger ship: P11-02458 VEGAYACHT $100.8 \mathrm{~m}$ KUSCH YARD, Verification of Structural details (Part B) and Primary Structure (Part C), December 2011.

Technical Report 102-302: Optimization, 2011c. Fullship 3D FE analysis of passenger ship- P09-01624 VEGAYACHT V853-Optimization, December 2011.

Technical Report 102-300: LR-3, 2012a. Full ship FE analysis of passenger ship: P11-02458 VEGAYACHT 100.8 m KUSCH YARD_Aft ship Response Analysis, January, 2012.

Technical Report 102-301: VIB-1, 2012b. Full ship FE analysis of passenger ship: P11-02458 VEGAYACHT $100.8 \mathrm{~m}$ KUSCH YARD, Global/Local Free Vibrations Analysis, February 2012.

Technical Report 102-302: Optimization, 2012c. Full-ship 3D FE analysis of passenger ship-P11-02458 VEGAYACHT $100.8 \mathrm{~m}$ KUSCH YARD-Optimization, April, 2012

Zanic, V., Das, P.K., Pu, Y., Faulkner, D. 1993. Multiple criteria synthesis techniques applied to reliability based design of SWATH ship structure. Integrity of Offshore Structures 5 (Chapter 18), Faulkner, Das, Incecik, Cowling, editors, EMAS Scientific Publications, pp. 387-415, Glasgow.

Zanic, V., Andric, J., Prebeg, P. 2009. Design Environment for Structural Design: Application to Modern Multideck Ships. Proceedings of the Institution of Mechanical Engineers Part M: Journal of Engineering for the Maritime Environment. M1, 223: 105-120.

Zanic, V., Andric, J., Prebeg, P. 2013. Design Synthesis of Complex Ship Structures, Ships and Offshore Structures, 8(3-4): 383-403.

Zanic, V. 2013. Methods and concepts for the multi-criteria synthesis of ship structures, Ships and Offshore Structures, 8(3-4): 225-244. 